\title{
O APAGAMENTO DO CORPO-ARQUIVO
}

\section{Helano Jader Cavalcante Ribeiro ${ }^{1}$}

Resumo: Por queima de arquivo entendemos comumente a execução de uma testemunha importante que pode denunciar os autores de um delito. Apagar 0 arquivo, dessa forma, é destruir as pistas do crime. Aquele que detém o arquivo, nesta lógica, detém o poder, ou a potência de mudar a história. Apagase o detentor do arquivo, ou o arconte, porque se acredita, através de uma transferência de valores, extinguir o próprio arquivo. Este foi o movimento nacional-socialista. A este pensamento nos guiará criticamente o texto de DidiHuberman: Das Archiv brennt - O arquivo queima. Desta forma, verificaremos como os conceitos de anacronismo e arquivo dialogam em nome da preservação e trato crítico do arquivo. A discussão teórica será perpassada, principalmente, pelo pensamento de Didi-Huberman e Jacques Derrida.

Palavras-chave: arquivo; anacronismo; nacional-socialismo.

Abstract: By file burning commonly understand the execution of an important witness who may denounce the perpetrators of a crime. Delete the file, therefore, it is to destroy the clues of the crime. One that holds the file in this logic, has the power, or the power to change history. Goes out the holder of the file, or the archon because it is believed, by transferring values, extinguish the file itself. This was the national socialist movement. The thinking in this critically guide the text Didi-Huberman: Das Archiv brennt - The burning file. Thus, we find how the concepts of anachronism and file dialogue in the name of preserving and critical file tract. The theoretical discussion is permeated mainly by the thought of Didi-Huberman and Jacques Derrida.

Keywords: archive; anachronism; National Socialism.

\footnotetext{
${ }^{1}$ Professor Assistente de Língua Alemã do Centro de Letras e Comunicação da Universidade Federal de Pelotas (UFPEL). E-mail: hjcribeiro@gmail.com
} 


\section{Introdução}

A crítica de Jacques Derrida ao pensamento ocidental opera numa linha que reconhece o logos em seus movimentos mais limitados, ou seja, capta a razão e sua manifestação mais maquínica e fechada: aponta logos e phoné como duas forças únicas responsáveis pelo direcionamento do pensamento ocidental, da metafísica e suas fixações inalteráveis. As verdades logocêntricas - a metafísica da presença - termo cunhado por ele em sua Gramatologia, representam o dispositivo que limita o jogo da disseminação dos sentidos. Neste trabalho, Derrida se dedicará, essencialmente, à desconstrução dos bases aparentemente inabaláveis da metafísica ocidental, ao mostrar a falibilidade dos binômios clássicos como natureza $x$ cultura, presença $x$ ausência, significante $x$ significado, consciente e inconsciente. Ao princípio, no capítulo intitulado "Lingüística e Gramatologia", arquiteta seu movimento desconstrutivo em torno do estruturalismo, do Curso de Línguistica Geral de Ferdinand de Saussure:

Derivada porque representativa: significante do significante primeiro, representação da voz presente a si, da significação imediata, natural e direta do sentido (do significado, do conceito, do objeto ideal ou como se queira). Saussure retoma a definição tradicional da escritura que já em Platão e em Aristóteles se estreitava ao redor do modelo da escritura fonética e da linguagem de palavras. (DERRIDA, 2011, p.37)

A Antiguidade Clássica já encarcerara a escritura. No diálogo Fedro, Platão aponta para a escritura como uma subversão do real potente, um mal, um risco para a formação de sua moגıs [pólis]. A linguagem escrita se revela ameaçadora, porque teria o poder de igualar medíocres a sábios e sofistas: pela e na escrita qualquer um - uma qualquer singularidade - poderia mostrar sabedoria, desta forma todos poderiam ser sofistas. A escritura também 
possibilita a alucinação dos sentidos e interpretações, que mascaram ou corrompem o mundo real, ou seja, a escrita é um mal, um simulacro amaldiçoado da linguagem falada, da phoné. Um veneno para Platão, a escritura surge como um meio, através do qual, Derrida irá con-fiar seu pensamento crítico.

A escritura, ainda maldita na modernidade, representa perigo. Ela é associada ao vazio, ao silêncio, ao jogo, podendo, assim, resistir, subverter. Foi preciso, muitas vezes na história, destruir, apagar, eliminar o arquivo degenerado, a escritura rebelde que fosse capaz de desestruturar os fechamentos, os estados de exceção. É porque ela própria pode montar seu estado de exceção. Fez-se necessário, nessa lógica, queimar o arquivo, reduzilo a cinzas, ao pó.

\section{Queima de arquivo}

Queima de arquivo pode ser entendido comumente pela execução de uma testemunha importante e que poderia denunciar executores de um delito. Apagar o arquivo, dessa forma, é apagar as pistas do crime. Aquele que detém o arquivo, nesta lógica, detém o poder, ou a potência de mudar a história. Apaga-se o detentor do arquivo, ou o arconte (e nesse caso, arquivo e arconte se confundem), porque se acredita, através de uma transferência de valores, extinguir o próprio arquivo. Do morto só restam cinzas e as cinzas, ao contrário do que se pensa, não são apenas o resultado de um arquivo extinto, mudo. As cinzas falam pelo morto secretamente.

O primeiro arquivo da história do Ocidente ardeu em chamas na antiga Atenas. Aconteceu no ano de 480/479 a.C. e foi incendiado pelos persas. Tudo o que restou foi cinza. As cinzas são como o passado que a cada momento é levado pelo vento para longe de nós. A cinza, no entanto, pode voltar a queimar a qualquer instante: "Mas essas cinzas são ainda alguma coisa, são formas, poemas, histórias. Elas se lembram ainda das chamas de onde 
nasceram, das quais restam." (DIDI-HUBERMAN, 1998, p.186). Não é um absurdo, as cinzas trazem o segredo e, por si só, sussurram-no sobre a destruição do arquivo e seu algoz, elas nos permitem uma leitura anacrônica, através dessa imagem dialética dos eventos, impondo no lugar de chrónos o kairós ${ }^{2}$, um tempo de devires-loucos e intensos.

Georges Didi-Huberman apega-se ao anacronismo positivo, atropela 0 tempo cronológico, chrónos, em nome da reconstituição do arquivo, através de suas imagens dialéticas, situando-as como ponto central do pensamento sobre o tempo. Ele questiona o uso dado pela história da arte dos modelos temporais propostos pela disciplina história e propõe, desta forma, a noção de anacronismo como um novo modelo de temporalidade a ser utilizado pela história da arte. O arquivo, segundo Didi-Huberman não é apenas um passivo reflexo do real, mas sim uma escritura, potente, repleta de sintaxe e ideologia. Para ele, as imagens são ricas de memórias, compostas por montagem de tempos diferentes, uma mistura que se liga através do anacronismo, atravessando seus platôs. O anacronismo relaciona-os dialeticamente, fugindo do modelo da continuidade.

Desse modo, devemos pensar no arquivo e suas cinzas como a imagem da barbárie dominante do século $X X$, o controle e manipulação do arquivo no Terceiro Império alemão, ou a conversão da escritura em nome de um logos a serviço do pensamento nazista.

Publicado em 2007, Das Archiv brennt ${ }^{3}$ [O arquivo queima] é composto por dois ensaios dos pensadores Georges Didi-Huberman e Knut Ebeling que nos fazem refletir sobre o conceito de arquivo e sua destruição. O primeiro aponta para o desastre dos campos de concentração, que foi documentado não somente pela memória, mas, acima de tudo, pela técnica, pela máquina,

\footnotetext{
${ }^{2}$ Mesmo que chrónos tenha sido a palavra comum entre nós, não é a única para designar o tempo entre os gregos. Outra é kairós, que significa medida, proporção, e, em relação com o tempo, momento crítico, temporada. Uma terceira palavra é aión, a mesma que Platão usa para se referir à eternidade na passagem no diálogo Timeu, um tempo sagrado e eterno, sem medidas.

${ }^{3}$ Todas as traduções são minhas.
} 
através da câmera fotográfica, "O arquivo queima". O que nos impõe a pergunta: trata-se aqui de documentar o indocumentável? Representar 0 irrepresentável através de imagens? O segundo elabora seu pensamento em torno do apagamento do arquivo, "As cinzas do arquivo": o que dizem esses arquivos de Auschwitz que tiveram que ser enterrados por seus próprios habitantes, o que nos diz tal cultura que necessita ocultar seus arquivos?

A dificuldade de todo pensamento do passado consiste não somente no fato de termos conhecimento de apenas uma pequena e fugaz parte dele, conhecemos apenas partes que se comportam em relação ao passado como as cinzas com o queimado. Os farrapos acidentais, que permaneceram, são torvelhinhados por processos e dispositivos, que com eles possuem um vínculo tão grande como os desenhos de carvão com o carbonizado. ${ }^{4}$ (EBELING, 2007, p.43-44).

Cinza e pedra, conceito e instituição, filosofia e arqueologia são uma aliança inflamável que não só desvelam a extinção do arquivo ateniense, mas também remontam ao controle total e destruição do arquivo imposto pelo nacional-socialismo. Os relatos de Auschwitz, escritura que surgiu no epicentro da catástrofe, formam um imenso arquivo: são testemunhos que não podem ser fechados em um sistema verdadeiro e absoluto, mas que viabilizam a imaginação do inimaginável. Trata-se aqui de um saber [e como todo saber, um poder], que em grande parte ficou perdido na terra, nas cinzas. $O$ trabalho de escavação, através dos relatos, é um trabalho arqueológico, representa a busca por uma arché, origem, mas que não se revela no sentido de Beginn [origem, começo], tampouco de Herkunft [procedência], é uma tentativa de leitura de uma história em ruínas e sua discussão crítica no tempo de aqui e agora, uma agoridade intensa e repleta de história.

É preciso, segundo Didi-Huberman, analisar a proliferação dos relatos não somente em sua forma quantitativa, mas também qualitativa, para a construção de um arquivo do desastre:

\footnotetext{
${ }^{4}$ Die Schwierigkeit jedes Denkens der Vergangenheit besteht also nicht nur darin, dass wir nur einen verschwinden geringen Teil Von ihr kennen, dass wir nur Teile kennen, die sich zum Gewesenen verhalten wie die Asche zum Verbrannten. Die zufälligen Fetzen, die geblieben sind, werden auch noch durch fremde Vorgänge und Vorrichtungen verwirbelt, die mit ihnen so viel zu tun haben wie eine Kohlezeichnung mit dem Verkohlten.
}

|81 Revista Eletrônica Literatura e Autoritarismo, no 25 - janeiro a junho de 2015 - ISSN 1679-849X http://cascavel.ufsm.br/revistas/ojs-2.2.2/index.php/LA/index 
Consistia na possibilidade de reprodutibilidade, em que foram transcritos e espalhados, continuamente, e em toda parte, os fatos, as listas, os nomes e suas cópias sob as cinzas dos campos de concentração. [...] os rastros de todos os tipos deveriam ser reunidos, para certificar do grande massacre ocorrido. Textos obviamente estão aí inclusos - com um já existente espectro de formas: fragmentário, sistemático, literário ou real - mas também restos de corpos como, por exemplo, dentes, que haviam sido espalhados por todos os lados, de modo que a própria terra pudesse certificar 0 ocorrido. (DIDI-HUBERMAN, 2007, p. 29) ${ }^{5}$

Ou seja, o corpo, entendido como uma linguagem, também é escritura, arquivo. O controle do corpo, da vida, era um projeto para formação do mito nazista, visto que o pensamento nacional-socialista fundamentou-se antes na biologia do que na filosofia. As aspirações nazistas dizem respeito, essencialmente, ao controle do corpo, ao controle da vida: biopolítica.

O conceito de biopolítica foi pensado, primeiramente por Michel Foucault, no primeiro volume de sua História da Sexualidade. A ideia de biopolítica veio se juntar às reflexões sobre as práticas disciplinares, ambas técnicas de exercício de poder, particularmente a partir do século XVIII e XIX. As disciplinas se voltavam para o indivíduo, e para o seu corpo, para a sua manipulação e adestramento através das diversas instituições modernas que perpassavam o indivíduo - como a escola, a fábrica, o hospital, a prisão Eram instituições que domesticavam, vigiavam e puniam os corpos e os tornavam aptos à produção industrial e econômica, ao controle do Estado, ou seja, peças fundamentais para a produção capitalista.

No entanto, foi principalmente no livro Vigiar e Punir e nos cursos que ministrou no Collège de France, nos anos de 1970, que Foucault mostrou como

\footnotetext{
${ }^{5}$ Es ging um die Möglichkeit der Reproduzierbarkeit, indem beispielsweise doe Fakten, die Listen, die Namen, die Pläne unablässig abgeschrieben und diese Kopien überall unter der Asche des Lagers vertreut wurden. Doch auch qualitativ: Alle Spurenarten sollten versammelt werden, um das Große Massaker zu bezeugen. Texte selbstverständlich - mit einem bereits sehr breiten Formenspektrum, ob fragmentarisch, systematisch, literarisch oder faktisch - aber auch stoffliche Reste, Zähne zum Beispiel, die überall verstreut wurden, damit die Erde selbst eines Tages archäologisch bezeugen könnte, was dort geschehen war.
} 
surgiram, a partir do século XVII, técnicas de poder que se legitimavam a partir do controle do corpo dos indivíduos. Foucault irá chamar esses mecanismos dispositivos de controle - de disciplinas, "métodos que permitem o controle minucioso das operações do corpo, que asseguram a sujeição constante de suas forças e lhe impõem uma relação de docilidade-utilidade." (FOUCAULT, 1998, p. 134). Desta forma, Foucault conclui acerca de seu conceito de biopolítica:

Se pudéssemos chamar de 'bio-história' as pressões por meio das quais os movimentos da vida e os processos da história interferem entre si, deveríamos falar de 'biopolítica' para designar o que faz com que a vida e seus mecanismos entrem no domínio dos cálculos explícitos, e faz do poder-saber um agente de transformação da vida humana. (FOUCAULT, 1998, p. 134)

Giorgio Agamben, em Homo Sacer: o poder soberano e a vida nua I, distingue, no contexto da cultura grega, duas dimensões díspares da vida humana: a zoé, ou vida nua, é entendida como a vida regida pelas leis da espécie, submissa à natureza que define o seu modo de ser - uma vida natural. Ela delineia a vida do corpo e seus simples desejos fisiológicos existe fora da vontade humana e da liberdade e da cultura. A bíos nada tem a ver com essa vida nua, ela ultrapassa a zoé, na medida em que é uma vida política. Quando Platão e Aristóteles mencionam três significados distintos em sua obra para a palavra bíos, parece que "não estava em questão de modo algum a simples vida natural, mas uma vida qualificada, um modo particular de vida." (AGAMBEN, 2002, p. 9)

O nazismo foi um regime que não se sustentava ideologicamente na filosofia, mas sim na biologia: "porque o nazismo negou a filosofia não de uma maneira genérica mas em favor da biologia." (AGAMBEN, 2008, p. 14). O fundamento primordial de ação dos soldados $S S$ foi, de forma radical, através de Auschwitz e dos outros diversos campos de concentração, a redução da chamada bíos em zoé, ou, como diz Agamben acerca dos chamados 
muçulmanos $^{6}$ : "O muçulmamo é o não-homem que habita e ameaça todo ser humano, a redução sinistra da vida humana à vida nua." (AGAMBEN, 2008, p. 56)

Os muçulmanos, no contexto da Segunda Guerra Mundial, eram os seres quase abjetos que povoavam Auschwitz, eram considerados figuras pelo simples fato de apresentarem corpos semelhantes a bonecos, já quase não possuíam aspectos que os caracterizassem como seres-humanos. 0 Muselmann era uma espécie de morto-vivo, ou inumano, que nos campos de concentração se encontrava em um estágio difícil de ser definido como humano. Agamben continua: "o muçulmano é um ser indefinido, no qual não só a humanidade e a não-humanidade, mas também a vida vegetativa e a de relação, a fisiologia e a ética, a medicina e a política, a vida e a morte transitam entre si sem solução de continuidade." (AGAMBEN, 2008, p 56). Auschwitz era, dessa forma, um espaço de fechamento, através de seus portões, ou uma fábrica de cadáveres:

Em todo caso, a expressão "fabricação de cadáveres" implica que aqui já não se possa propriamente falar de morte, que não era morte aquela dos campos, mas algo infinitamente mais ultrajante que a morte. Em Auschwitz não se morria: produziam-se cadáveres. Cadáveres sem morte, não homens, cujo falecimento foi rebaixado a produção em série. (AGAMBEN, 2008, p. 78)

Roberto Esposito (2004) esclarece, ao elucidar seu conceito de tanatopolítica - política da morte -, que para ele parece ser paradoxal um conceito de biopolítica, controle do corpo, em que não há desejo de preservação da vida, mas sim de sua aniquilação. No livro de Hitler Mein Kampf, uma das primeiras escrituras ideológicas do nazismo, surge a noção do aperfeiçoamento do corpo, através da expressão predileta do Führer,

\footnotetext{
${ }^{6}$ No âmbito de Auschwitz, a palavra muçulmano poderia ser entendida pela postura destes inumanos pelo fato de ficarem encolhidos no chão, ao dobrarem suas pernas como orientais, além da rigidez quase cadavérica do seu rosto. Outra leitura, um tanto mais imaginativa, seria a derivação da palavra Muschelmann [homem concha] graças ao mesmo movimento de encolhimento do corpo.
} 
körperliche Ertüchtigung [capacitação física], como uma referência direta ao preparo físico do corpo, acima do Geist [espírito, intelecto], que se torna uma das diretrizes básicas do seu projeto de educação do povo alemão: preparar o corpo, a vida, para usá-la: preserva-se e controla-se o corpo ariano, controla-se e destrói-se o corpo do judeu.

\section{0 corpo queima}

O dia 10 de maio de 1933 foi o auge da perseguição dos nazistas aos intelectuais, principalmente aos escritores como Thomas Mann, Stefan Zweig entre outros representantes do pensamento. Da mesma forma, obras de intelectuais judeus como Sigmund Freud e Albert Einstein foram queimadas. Em toda a Alemanha, montanhas de livros e suas cinzas se amontoavam nas praças. Hitler e seus oficiais pretendiam através deste gesto destruir o arquivo degenerado para a construção de um novo no Estado nazista. Eles possuíam um pensamento organizado, baseado na construção de um mito, o da civilização ariana dos alemães. Dentro desta organização encontra-se a tentativa de Hitler de estetização da política ${ }^{7}$. Era preciso, segundo os nazistas, queimar o arquivo, converter a escritura degenerada em um logos a serviço do nacional-socialismo.

Todo tipo de pensamento e construção de sentido que fosse de encontro à ideologia nazista deveria ser combatido e silenciado. Toda a idealização da fundação do estado nazista é baseada na criação de um mito arrebatador do povo alemão. Hitler, em seu livro, expõe o que seriam as primeiras doutrinas para o povo alemão que possibilitariam criar esse mito: a construção de um novo arquivo totalizador e toda a construção de um pensamento. Se a Alemanha aos olhos dele ainda não existia, deveria ser inaugurada a partir de um modelo, que para Hitler foi a mimese da civilização grega. Para isso, o Estado nazista valeu-se de toda uma simbolização, imagens - através da

\footnotetext{
${ }^{7}$ Walter Benjamin opõe-se a essa estetização da política (fascista) e em seu lugar propõe a politização revolucionária da arte. 
suástica, da águia, de bandeiras, uniformes, saudações - para a construção de um sonho, com o qual o povo alemão pudesse se identificar.

Outro elemento fundamental para a construção do pensamento nazista é a existência de um tipo. Jean-Luc Nancy em parceria com Philippe LacoueLabarthe alegam, em seu livro, $O$ mito nazista, que o mito e o tipo são indissociáveis. Mas o que entender por tipo? O tipo nos remete à questão da Gestalt [forma], que nos remete à raça. Eis aí sua importância para a ideologia nazista, pois "a raça é a identidade de uma potência de formação, de um tipo singular; uma raça é o portador de um mito." (NANCY; LACOUE-LABARTHE, 2002, p.51-52). Hitler sabia que essa era a justificativa definitiva para a exclusão do Estado nazista dos impuros como os judeus.

Auschwitz foi o espaço em que toda a ideologia e arquivo nazistas puderam impor sua super-representação ${ }^{8}$ contra a representação judia. JeanLuc Nancy desenvolve essa ideia ao denominar a representação judia de representação proibida. Para Hitler a representação judia era pejorativa e por isso deveria ser eliminada. A força de imposição, oriunda das tropas da SS, encarregava-se de fazer valer a super-representação hitlerista e a coação dos prisioneiros:

Auschwitz é um espaço organizado para que a presença em si mesma, a que é exibida e mostra o mundo com ela e sem descanso, se dê o espetáculo de aniquilar aquele que, em princípio, carrega com 0 interdito da representação, ou então o que aqui chamei de representação proibida. Os oficiais SS estão lá para reprimir o que possa surpreender, interpelar ou deixar atônita a ordem super-representante. (NANCY, 2007, p.48) ${ }^{9}$

Ao final da guerra, a queima de arquivo não cessou. Os soldados nazistas ficaram encarregados de apagar, destruir, tudo que pudesse

\footnotetext{
${ }^{8}$ Através do mito ariano Hitler pôde instalar a representação do Reich alemão.

${ }^{9}$ Auschwitz es un espacio organizado para que la Presencia misma, la que se muestra y muestra el mundo con ella y sin resto, se dé el espectáculo de aniquilar aquello que, por principio, carga con el interdicto de la representación, o bien lo que aquí he denominado la representación prohibida. Las SS están ahí para suprimir lo que puede sorprender, interpelar o dejar atónito al orden suprarrepresentante.
} 
denunciá-los: roupas, fotos, imagens, cartas, corpos. A ordem era de destruição total. Os corpos das vítimas dos campos deveriam sumir, visto que podiam falar tacitamente a respeito dos carrascos e de suas atrocidades. $O$ corpo/cinza também é escritura, tanto se in-screve, como se ex-creve [crava] na história. Destrói-se o corpo, porque, assim, apaga-se o locus da memória. Os restos dos corpos também queimam. A imagem da barbárie é denunciada, não somente por suas cinzas [há de se lembrar das cinzas, restos de cabelos, que caíam pelas chaminés, nas casas das pessoas que moravam nas proximidades dos campos de concentração], mas também pelos corpos feridos, marcados e já sem vida, que carregavam em si a história, o horror da Shoah, o que restou de Auschwitz.

\section{Conclusão}

O saber passa, primeiramente, pelo imaginar. A Endlösung [solução final] das tropas nazistas representou uma máquina de destruição impiedosa e de desimaginação generalizada. Os nazistas decidiram conscientes pelo apagamento de todos os rastros, ou seja, eliminar o arquivo para converter Auschwitz no inimaginável. No entanto, o arquivo do mal ainda queima: "Os arquivos da Shoah definem sem dúvida alguma um território incompleto, de sobrevivência, fragmentário, mas este território existe desde sempre."10 (DIDIHUBERMAN, 2004, p.43). Os nazistas estavam certos de que tornariam invisíveis os judeus e todo o massacre. Os campos foram laboratórios não somente de controle e morte, mas também de desaparição generalizada. O arquivo de imagens - fotos, cartas e relatos - sobrevive. Ele não somente permite uma leitura anacrônica e a denúncia da barbárie, mas também nos possibilita imaginar o inimaginável.

${ }^{10}$ Los archivos da la Soah definen sin Duda alguna un território incompleto, de supervivência, fragmentário; pero este território, desde luego, existe. 


\section{REFERÊNCIAS}

AGAMBEN, Giorgio. Homo Sacer. Poder soberano e vida nua. Tradução de Henrique Burigo. Belo Horizonte: UFMG, 2002.

AGAMBEN, Giorgio. O que resta de Auschwitz: o arquivo e a testemunha (Homo Saccer III). Tradução de Selvino J. Assman. São Paulo: Boitempo, 2008.

DERRIDA, Jacques. Gramatologia. Tradução de Miriam Chnaiderman e Renato Janine Ribeiro. São Paulo: Perspectiva, 2011.

. Mal de arquivo: uma impressão freudiana. Tradução de Cláudia de Moraes Rego. Rio de Janeiro, Relume Dumará, 2001.

DIDI-HUBERMAN, Georges; EBELING, Knut. Das Archiv brennt. Berlin: Kultur Verlag Kadmos, 2007.

DIDI-HUBERMAN, Georges. O que vemos, o que nos olha. Tradução de Paulo Neves. São Paulo: Ed. 34, 1998.

Imagenes pese a todo. Memorial visual del Holocausto.

Tradução de Mariana Miracle. Barcelona: Ediciones Paidós Iberica, 2004.

ESPOSITO, Roberto. Bios: biopolítica e filosofia. Tradução de M. Freitas da Costa. Lisboa: Edições 70, 2004. 
FOUCAULT, Michel. História da Sexualidade I: a Vontade de Saber. Tradução de Maria Thereza da Costa Albuquerque e J. A. Guilhon Albuquerque. Rio de Janeiro: Graal, 1998.

LACOUE-LABARTHE, Philippe; NANCY, Jean-Luc. O mito nazista. Tradução de Márcio Seligmann-Silva. São Paulo: Editora lluminuras, 2002.

NANCY, Jean-Luc. La representación prohibida. Tradução de Margarita Marínez. Buenos Aires: Amorrortu, 2007. 